\title{
Assuring quality
}

\author{
K. A. Eaton, ${ }^{1}$ P. A. Reynolds, ${ }^{2}$ R. Mason, ${ }^{3}$ R. Cardell ${ }^{4}$
}

IN BRIEF

- This paper considers how the quality of higher education in general, and dental education in particular, is assessed.

- It then considers how the principles of quality assurance have been applied to dental distance learning.

- It concludes that, to date, it appears that relatively little work has been done to formulate quality guidelines for elearning in dentistry.

All those involved in education have a strong motivation to ensure that all its aspects, including content and teaching practice, are of the highest standard. This paper describes how agencies such as the Quality Assurance Agency for Higher Education (QAA) and the General Dental Council (GDC) have established frameworks and specifications to monitor the quality of education provided in dental schools and other institutes that provide education and training for dentists and dental care professionals (DCPs). It then considers quality issues in programme and course development, techniques for assessing the quality of education, including content and presentation, and the role of students. It goes on to review the work that has been done in developing quality assessment for distance learning in dentistry. It concludes that, to date, much of the work on quality applies to education as a whole and that the assessment of the quality of e-learning in dentistry is in its infancy.

\section{E-LEARNING IN DENTISTRY}

Section A: Teaching and technology

1. A description of the new technologies used in transforming dental education

2. Seeing is believing: dental education benefits from developments in videoconferencing

3. Webcasting: casting the web more widely

4. Top of the pops - CD-ROM and DVDs in dental education

Section B: Informatics: better informed by systems and services

5. Better informed: an overview of health informatics

6. Better informed in clinical practice a brief overview of dental informatics

7. Digital clinical records and practice administration in primary dental care

Section C: Impact of e-learning in

dental education

8. Remember the days in the old school yard: from lectures to online learning

9. An intricate web - designing and authoring a web-based course

10. The many faces of interaction

11. Supporting the learner and teacher online

12. Making a mark - taking assessment to technology

13. Continuing professional development and ICT: target practice

14. Assuring quality

Section D: A connected future

15. Nine years of DentEd: a global perspective

16. A vision of dental education in the third millenium

\section{INTRODUCTION}

Quality assurance is now a familiar and regular feature of UK higher education. In the vast majority of cases, institutions have developed and refined systems of quality assurance and operate well-established internal processes for assuring the standard of any award and the quality of the student experience. The external examiner system, processes for validation, annual and periodic review, student surveys and feedback and relatively transparent systems of governance are all in place and are routinely described in institutional quality handbooks.

The Quality Assurance Agency for Higher Education (QAA), established in 1997 to provide 'an integrated quality assurance service for UK higher

'Visiting Professor, UCL Eastman Dental Institute, 256 Gray's Inn Road, London, WC2 1HH/Honorary Professor, University of Kent; ${ }^{2 *}$ Professor of Dental Education, ${ }^{4}$ Strategic Quality Adviser, Centre for Flexible Learning in Dentistry, King's College Dental Institute, Floor 3 Strand Bridge House, 138-142 Strand, London, WC2 $1 \mathrm{HH} ;{ }^{3}$ Professor of Educational Technology, Institute of Educational Technology, The Open University, Walton Hall, Milton Keynes, MK7 6AA

${ }^{*}$ Correspondence to: Professor P. A. Reynolds Email:P.A.Reynolds@kcl.ac.uk

\section{Refereed Paper}

DOI: 10.1038/sj.bdj.2008.662

${ }^{\circ}$ British Dental Journal 2008; 205: 145-150 education', undertakes institutional-level audit and review on a cyclical basis that is 'intended to ensure that institutions are providing higher education, awards and qualifications of an acceptable quality and an appropriate academic standard; and exercising their legal powers to award degrees in a proper manner'. ${ }^{1}$ The QAA's academic infrastructure additionally provides a 'means of describing academic standards in UK higher education'. It comprises:

- Code of practice for the assurance of academic quality and standards in higher education

- Frameworks for higher education qualifications in England, Wales and Northern Ireland, and in Scotland

- Subject benchmark statements

- Programme specifications

- Progress files. ${ }^{1}$

The Research Assessment Exercise (RAE) provides yet another element of scrutiny and review of UK higher education institutions. Jointly conducted by the Higher Education Funding Council for England (HEFCE), the Scottish Funding Council (SFC), the Higher Education Funding Council for Wales (HEFCW) and the Department for Employment and 
Learning, Northern Ireland (DEL), its primary purpose for the 2008 exercise is to "produce quality profiles for each submission of research activity made by institution. ${ }^{2}$

For healthcare, medical and dental education and research there is the further dimension of the application of professional body accreditaion and related quality assurance processes. The General Dental Council (GDC) has established its own frameworks and specifications to monitor the quality of education provided in dental schools and other institutes that provide education and training for dentists and dental care professionals (DCPs). For the undergraduate course, the framework is called The first five years. ${ }^{3}$ It 'aims to ensure that universities provide modern systems of education and clinical training. ${ }^{3}$ Its comprehensive guidelines are enforced by regular dental school inspections. A similar inspection regime also covers dental schools that offer postgraduate courses.

\section{BENCHMARKING}

The principles behind The first five years are embodied in Subject benchmarks for dentistry ${ }^{4}$ issued by the QAA. There is also a similar QAA publication for DCPs. ${ }^{5}$ Prepared under contract for the Higher Education Funding Council (HEFC), they set the guidelines for dental education by stating the 'expectations about standards of degrees'. They describe 'what gives a discipline its coherence and identity, and define what can be expected of a graduate in terms of techniques and skills needed to develop understanding in the subject."

Benchmarks aim to encapsulate the best practice and objectives involved in teaching and learning; they are, therefore, likely to be continually updated. According to the QAA, their prime importance is as an 'external source of reference when new programmes are being designed and developed.' ${ }^{4}$ They also "provide general guidance for articulating the learning outcomes... but are not a specification of a detailed curriculum.' They enable the established learning outcomes to be reviewed and evaluated against set standards and in so doing, they "provide support in the pursuit of internal quality assurance."

\section{QAA CODE OF PRACTICE}

The QAA has also paid specific attention to distance and e-learning as part of a Code of Practice. ${ }^{6}$ This consists of 'interrelated documents' which offer advice on the management of academic quality and standards. The code addresses e-learning under the generic title of 'flexible and distance learning' (FDL) and identifies a number of aspects relating to FDL. These are:

- The delivery of an FDL programme of study

- The learning support available to the student

- The assessment of the student's achievement.

Interestingly, the QAA has decided not to prepare separate guidance on the quality assurance of e-learning, arguing "that most of the questions that need to be asked, and answered, about academic management are common to both elearning and other FDL methods. ${ }^{6}$

On the subject of e-learning, the Code of Practice makes the point that remote delivery must be fit-for-purpose, secure and reliable, and study materials distributed via the web must "meet the specified expectations of the awarding institution in respect of the quality of teaching and learning support material for a programme or element of study leading to one of the awards. ${ }^{6}$

This comparatively brief survey of the quality framework should not hide the fact that the onus is very much placed on the course providers to ensure that the standards are met, irrespective of the discipline. Provider institutions in turn have their own codes and protocols for quality assurance. The Open University, for example, has a Quality and Standards Board that 'approves and reviews the overall University arrangements for the management of quality and standards and its strategy for quality assurance and ensures that quality is maintained and cross-unit quality-related issues are properly addressed and satisfactorily resolved."7 One of the Open University's protocols, The framework for academic quality and standard, ${ }^{8}$ incorporates the QAA directives, for example, 'a set of generic level indicators to support curriculum design, and teaching and learning development within the OU at undergraduate levels 1,2 and 3.'

\section{PROGRAMME AND COURSE DEVELOPMENT}

However, much of this attention to quality is about procedures and approaches. Important as these are - one definition of quality assurance is that it 'achieves defined standards through application of agreed procedures'9 - of course, these are not the sole determinants of who gets top marks! As a recent study has claimed that 'For almost half of the respondents benchmarking was not leading to quality improvements and as one academic put it: "the things that actually get altered are very much exterior gloss rather than genuine content of teaching methods." 10

Assessing programme quality in all its aspects is a difficult task. It is a nebulous concept, one of the problems being that 'there are a number of different ways of defining the term quality. Nevertheless, a consensus appears to be forming around the view of quality as "fitness for purpose." 9

The situation is further complicated by the dearth of hard evidence, for, as one study asserts, 'There are few empirical studies that offer quantifiable data on program quality.'11 Assessing such quality is a difficult task, compounded by the abstract and personal nature of any reaction: what is good quality for one person may not be for another. This possibly explains why most of the efforts devoted to quality in education are directed towards establishing the physical framework of standards, procedures and approaches, rather than judging and measuring the quality inherent in programmes, courses and material.

Despite this caveat, attempts are being made to ensure and assure this more abstract quality. A key element in this is evaluation; for many this lies at the heart of ensuring and assuring quality. In its broadest sense, evaluation can cover virtually every aspect of education. This all-encompassing nature is revealed in the quote 'Evaluation is used, or should be used, to enable institutions to operate as learning organisations. ${ }^{9}$ The same author reveals the scope of the subject 
by stating that 'While the course is, usually, the focal point of the programme provision, the students' experiences are determined by the sum total of all their instructions with the organisation which is providing the course. ${ }^{9}$ Within this defınition lies everything from accountability, through student statistics and teaching and support systems, to research.

It is not an easy topic to discuss and it has been said that 'Programme evaluation in the field of open and distance teaching is relatively undeveloped. ${ }^{9}$ However, as the use of e-learning increases, assessment of its quality will grow in importance. Warnings about the complexity of the task include: 'The program design process is a complex one, depending on several intersecting factors and strongly influenced by intangible variables that often become apparent only after the initial design process is completed and program facilitation is underway. ${ }^{, 12}$

As a starting point, a recommendation is that 'From the evaluation perspective it is helpful to view the process of course production and dissemination in three stages:'9

- Design

- Development

- Production.

At the design stage, a series of elements are recommended. These are: ${ }^{9}$

- Stakeholders in the evaluation

- Role of the evaluation

- Issues to be addressed

- Approach to be used

- Methodology to be used.

The development stage is concerned with course effectiveness, learning experience and course content and uses a number of evaluation techniques to judge these factors, including peer comment, development testing and piloting.

For course presentation a comparison is made between classroom-based learning and distance learning. In the former, measurements such as formal feedback from students, attendance at lectures and tutorials, the enthusiasm and knowledge displayed during these and the quality of work produced, together with formal assessment, are more readily

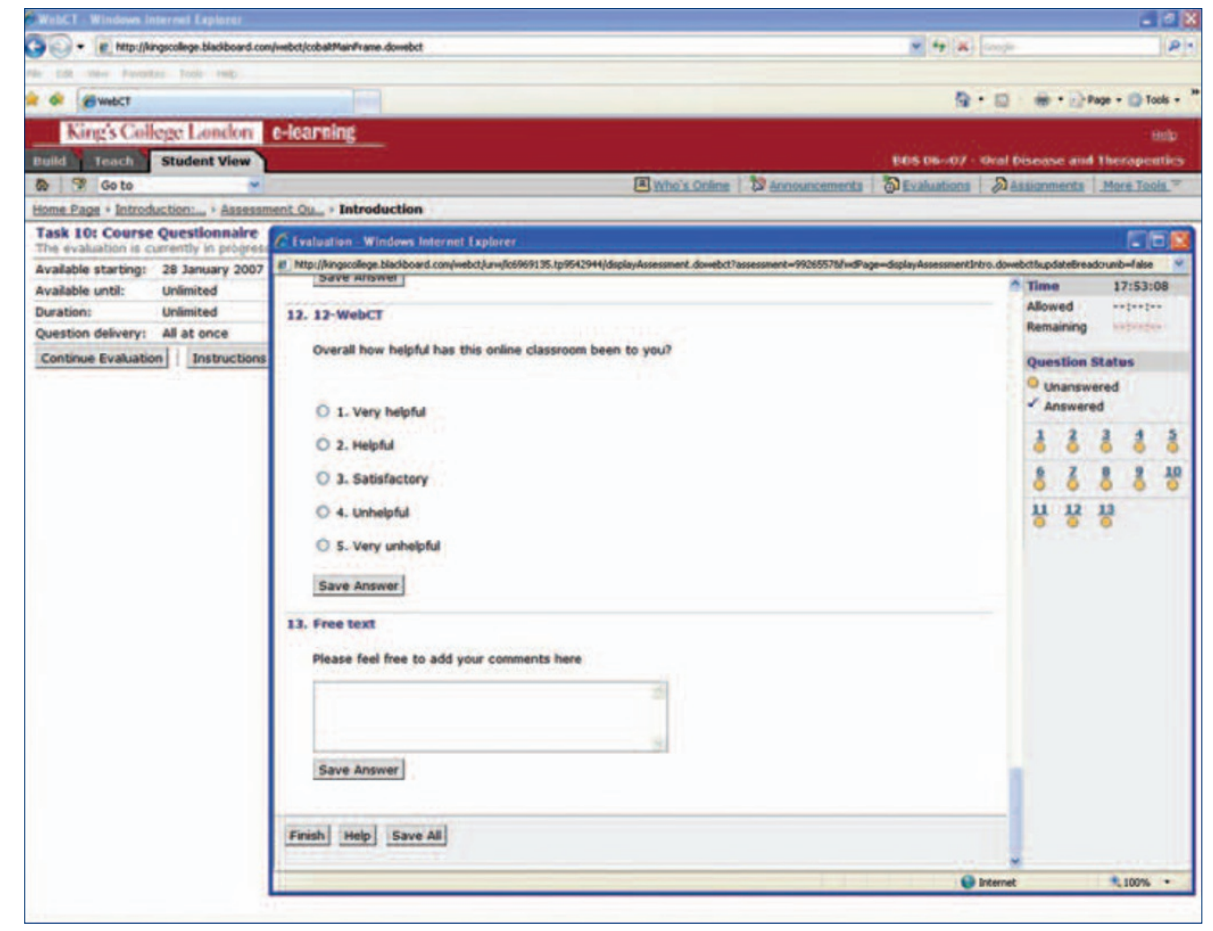

Fig. 1 Part of an online end of course questionnaire providing feedback from undergraduate dental students

available than in the latter. For distance learning many of these techniques are impossible to implement, as 'there is little or no direct contact between the course designers, the course providers and the students. ${ }^{9}$ For this reason the feedback from students is crucial.

\section{HOW DO YOU ASSESS QUALITY?}

The most common method utilised for assessing quality is questionnaire-based research, though not everyone regards the questionnaire as the panacea for all types of evaluation (Fig. 1). One criticism of the use of questionnaires to assess educational quality is summed up as: 'The flaw in this type of exercise is that students' views are only accessed at the end of their course, and the tutor, who can actually influence the quality of that cohort's student experience, is not actively involved in collecting students' views or given the opportunity to respond to them.'13

Instead, the same authors suggested that a more thorough combination of mid-course questionnaire surveys, endof-course surveys, end-of course questionnaires and focus group meetings, together with monitoring of student performance and drop-out rates, should be instituted. ${ }^{13}$ They also claimed that the mid-term questionnaires were a useful means of identifying any problems while there was still a chance to address solutions. However, in common with many evaluation questionnaires, it was acknowledged that by mid-course a proportion of students might have already dropped out of the system for a range of reasons. Consequently these students' opinions and unmet needs are lost to the organisation. Data on students' expectations and concerns can, however, be collected before students start courses and before they drop out. ${ }^{13}$

One authority has recommended that 'apart from subjecting the design of a course to any quality assurance procedures in force, ${ }^{14}$ the basis should be a programme specification developed to provide "clear and explicit information for students so that they can make informed choices about their studies and the levels they are aiming to achieve. ${ }^{14}$ This specification should cover:

- Programme aims

- Programme outcomes

- Programme structure

- Support for students and their learning

- Criteria for admission

- Methods for evaluating and improving the quality and standards of teaching and learning

- Assessment regulations. 


\section{PRESENTATION OF CONTENT}

For content, a leaf should be taken out of the US Army's book. Their approach is based on the assumption that high quality courseware is essential to the success of distance learning, irrespective of the medium through which it is delivered.'

The result is the insistence that several components must be included in all US Army courses, including the following:

- Contain instructions that grab attention

- Tell why tasks are important to learn

- Include consequences of good and of poor performance

- Provide context

- Contain questions requiring analysis, synthesis and evaluation.

A study into web-based adult education delineated six dimensions of programme quality, one of which is entitled 'quality of instruction'." The quality indicators for these were (and are):

- Designed to encourage critical thinking

- Developed and based upon clearly stated learning outcomes

- Designed to support independent learning

- Designed to accommodate the cultural differences among students

- Carefully maintained and updated

- Designed to accommodate the special needs of some students.

However, in relation to e-learning the authors remark that 'the average performance in this area (quality of instruction) may be attributed to the fact that web-based adult education is a newer mode of delivery that might not yet have gained the commitment of resources necessary to perpetuate quality of instruction. ${ }^{11}$

\section{Course materials (e-content)}

At a more detailed level, students need to have confidence in the quality of the course material and content. This is especially true of distance and elearning, which throws up problems of its own: for example, the question ${ }^{15}$ has been posed, 'Should e-learning material be treated in a similar manner to journal articles, or as a textbook, or should a [new] third way be devised?'
The authors of the paper concerned therefore suggested that there was a need for 'a new structured method of assessment. ${ }^{15}$ Their justification for this was that "There is currently no monitoring process for material that is published on the web, and that disk-based products [when they are reviewed] are usually considered along similar lines to a textbook.' In addition, they believed that the globalisation of educational media will require 'internationally agreed criteria for the evaluation of e-learning-based material. ${ }^{15}$

A similar theme is developed in a recent quality guide for distance learning material for dentists, ${ }^{16}$ which includes the observation: "little guidance is available to help its users to select quality material relevant to their needs.' The authors of the guide go on to claim "many of the more traditional quality standards and criteria are outdated or inappropriate. ${ }^{16}$

To address this situation, the authors produced the guide in which they posed three significant questions ${ }^{16}$ which were:

- Does the material encourage and enable effective learning?

- Are its contents scientifically correct?

- Is the technology user-friendly, reliable and durable?

With specific reference to the first question, the guide suggested that the material should: ${ }^{16}$

- Be coherent, clear and consistent, ie easy to follow

- Fit in with any wider programme it maybe a part of

- Develop thinking and learning skills, taking into account prior skills and knowledge

- Enable participants to reflect on new knowledge and skills in terms of their own professional experience

- Encourage participants to implement what they have learnt, ie improve practice.

In answer to the second question, the attributes of high quality material were listed as: $:^{16}$

- Correctly referenced

- Have an indication of the strength of evidence to support a particular view or procedure
- Wherever possible present the contrary view together with it supporting evidence

- Make it clear when it was last updated and reviewed.

\section{The students' role}

In the drive for quality in education it is not often realised that students have a part to play. This is as we have already seen, primarily through feedback from them, ie their comments and criticisms of courses and associated material.

According to the QAA, ${ }^{6}$ 'students should always have formal opportunities to feed back on the experience of their programme on a regular basis and FDL programmes are no exception.' The authors of The quality guide ${ }^{16}$ also highlighted the value of feedback in quality assurance by stressing that "participants should have an opportunity to give feedback'.

The QAA's recommended methods for this include responses channelled through local learner support groups, online surveys and web conferencing. ${ }^{5}$ The resultant information can be fed into reviews of the courses, the pedagogic methods and the material, leading to a continual process of updating courses and material to ensure the student experience is as high as possible, while at the same time enabling the latest educational thinking, subject ideas and technology are incorporated.

\section{PILOTING}

The quality guide stresses that "the distance learning material should be independently assessed (pre-piloted) before distribution to users. ${ }^{16}$ An example of how this can be achieved comes from the Open University where such a measure was undertaken for a distance learning language course. ${ }^{17}$ In the test (pilot), 'Enough sample materials were produced to simulate three tutorials for the process of development testing.' The main findings of the development testing process related to the type of activity, the need for structured materials which are consistent with course materials, the need for very clear instructions (both for tutors and students), the desire on the part of the students for a lesson plan to be available in advance, some "class 
rules' for behaviour online (again both for students and tutors), and that activities should maximise the opportunities for interaction. ${ }^{17}$

\section{OUTCOMES}

As e-learning continues to develop as an increasingly important vehicle for providing learning opportunities to diverse international audiences, do our policies and practices for assuring quality and standards remain valid and fit for purpose? What consideration do we need to give, if any, to adapting or enhancing well-established systems of QA exercised by UK Higher Education Institutes to ensure that content, programmes and awards delivered in an e-environment meet, and potentially exceed, the high standards expected in face-toface delivery? Are we confident that elearning is subject to the same rigorous requirements that apply to face-to-face learning or more established models of distributed and flexible learning? These questions are ones to be addressed by any educational provider but how are dental educators responding in this respect?

A QAA study provides the answer and, with a few caveats, awards high marks. Its subject overview report on dentistry ${ }^{18}$ presents the findings of the review between 1998 and 2000 provided by the dental schools in England and Northern Ireland.

In summary it found "the overall quality of higher education provision in dentistry... to be excellent.' It further observed that 'Across the six aspects of provision by far the most frequently awarded grade was Grade 4, the highest.' ${ }^{18}$

Teaching and learning was wellreceived and appreciated while the reaction of students was reported as "broad satisfaction both with their learning experience and the excellent academic and pastoral support they received. ${ }^{18}$ This response is reflected in the very favourable comment on the quality of student work.

The review considered seven key elements, which were: ${ }^{18}$

- Aims and objectives

- Curriculum design, content and organisation (92\% of the 12 institutions were awarded Grade 4)

Table 1 Example checklist to identify academic and clinical features of reusable learning objects before placing them in a repository

Academic/Clinical section

- Consider breakdown of content for defining reusable learning objects (RLO):

- If using whole course/module material, how can the material be broken down into academically viable component parts for use as RLOs for the repository?

0 confirm that RLO is viable as a free-standing object within the repository.

- Identify intended learning outcome of RLO

- Suggest academic context of RLO (relationship to unit/course at given level)

- Identify level

- Suggest learning hours attached to object

- Suggested assessment method for RLO

- Validity and accuracy of content

- Body of evidence to support validity

- Date of last review

- Type of review (internal/external peer review; internal/external audit)

- Review interval - internal \&t external

- Version control

- Standardisation of units, references, measurements, terms

- Inclusivity (cultural awareness, gender/ethnic balance)

- Links, acknowledgements

- Plagiarism issues (Turnltın®)

- Use of good and bad examples in themselves as LOs

- Known overlaps with other material in repository and relation to the RLO in question

- Identify overlaps with other materials in repository and potential relation to these.

Other sections not detailed here

Educational design

Contractual and legal issues

Technical considerations

- Teaching, learning and assessment

(all were awarded Grades 4 or 3)

- Student progression and achievement (92\% were awarded Grade 4)

- Student support and guidance

- Learning resources (92\% were awarded Grade 4)

- Quality management and enhancement (58\% were awarded Grade 4).

The last of these key elements elicited the main caveat in the report, which was that 'this aspect is the most variable of the six', ${ }^{18}$ evidenced by Grade 4 being awarded to $58 \%$ of the institutions and Grade 3 to $25 \%$.

The attention to quality, while extensive, is producing diverse results despite commitment from higher educational establishments. Unfortunately, with regard to e-learning, the application of formal quality programmes and standards is in its infancy in dentistry and, as a result, there is as yet no large body of evidence from which to make firm conclusions. More research is needed and, as the Higher Education Academy (HEA) observes, 'Demands for an evidence informed approach to policy and practice in $\mathrm{HE}$ are creating the conditions for more serious engagement with institutional research. ${ }^{19}$

At a European level, along with all aspects of undergraduate dental education, the issue of quality assurance has been addressed by the DentEd project. This project will be described and discussed in the next paper in the series. One working group has developed a 'European guideline for benchmarking and quality assurance in dental education. ${ }^{20}$

\section{NEW DIMENSIONS}

The capacity exists to reach a global network of students, practitioners and other providers. However, it is necessary to consider what other dimensions of quality assurance need to be in place within any institution where a third party is permitted to draw on content developed or processed by the originating institution to assist the third party in 
the development of its own programmes and courses. Under these circumstances, the originating institution is not acting as an awarding body, programme presenter or supporting institution, but as a provider of a learning objects repository. Issues relating to institutional management and assurance of high quality learning objects present particular challenges which need to be addressed.

Projects such as Quality for Reuse, Q4R $\mathrm{R}^{21}$ (http://www.q4r.org), provide a useful schema of best practice for the quality assurance of learning object repositories. The Q4R project aims to fulfil its vision 'to expand dissemination and reuse of high quality learning objects in a worldwide knowledge economy by offering a flexible, efficient and effective set of quality assurance processes and tools in collaboration with a global network of repositories' by providing 'tools, techniques, procedures, principles and strategies assisting in implementing quality assurance practices for high quality LOR'. For projects such as IVIDENT ${ }^{22}$ (International Virtual Dental School, http://www.ivident.info), where learning objects are at the heart of the flexible learning process, the need for high level quality assured learning objects is clear (Table 1). As such developments inevitably take centre stage and programme and course developers choose to build and customise provision to respond to their own particular educational contexts and requirements, the need for an appropriately quality assured product will be paramount.
For providers of e-learning and content for medical and dental education there are further issues to be addressed. Issues of patient confidentiality and consent, data protection and potential litigation arising from perceived or actual infringements of related legislation will need to be keenly considered by the relevant bodies within any higher education institute. It is therefore essential to ensure that QA systems seek assurance that the ramifications of delivering content through an e-environment have been addressed and resolved and that the need to consider such issues are firmly embedded in programme and content development.

In summary, it can be concluded that in the United Kingdom, quality assurance of higher education, including dental education, has been given considerable attention over the last 15 years. However, perhaps because it is relatively new, the mechanisms for assuring ICTbased dental education are at present under-developed and work is needed to correct this deficiency.

1. The Quality Assurance Agency for Higher Education: an introduction. http://www.qaa.ac.uk/aboutus/qaalntro/intro.asp (accessed 14 May 2008).

2. The Research Assessment Exercise website. www. rae.ac.uk (accessed 14 May 2008)

3. General Dental Council. The first five years: a framework for undergraduate dental education. 2nd ed. London: GDC, 2002.

4. The Quality Assurance Agency for Higher Education. Subject benchmarks for dentistry. Gloucester: QAA, 2000.

5. The Quality Assurance Agency for Higher Education. Subject benchmarks for dental care professionals. Gloucester: QAA, 2005

6. The Quality Assurance Agency for Higher Education. Code of Practice for the assurance of academic quality and standards in higher education. 2nd ed. Gloucester: QAA, 2004.

7. The Open University. Quality and standards in the
Open University. Fact sheet 1: institutional management of quality and standards. Milton Keynes: The Open University, 2004.

8. The Open University. Quality and standards in the Open University. Fact sheet 2: framework for academic quality and standards. Milton Keynes: The Open University, 2004.

9. Calder J. Programme evaluation and quality. A comprehensive guide to setting up an evaluation system. London: Kogan Page, 1995.

10. Pidock S. What is the impact of subject benchmarking? Active Learning Higher Educ 2006; 7: $111-128$.

11. Harroff P A, Valentine T. Dimensions of program quality in web-based adult education. Am J Distance Educ 2006; 20: 7-20.

12. Wiesenberg F, Stacey E. Reflections on teaching and learning online: quality program design, delivery and support issues from a cross-global perspective. Distance Educ 2005; 26: 385-404.

13. Stevenson K, MacKeogh K, Sander P. Working with student expectations of tutor support in distance education: testing an expectations-led quality assurance model. J Open Distance Learning 2006; 21: 139-152.

14. Fairhurst J. Quality assuring an electronically delivered distance learning programme. Paper delivered at the 17th BILETA Annual Conference, Amsterdam, April 2002. http://www.bileta.ac.uk/ pages/Conference $\% 20$ Papers.aspx

15. Oliver R, Paganelli C. Towards a global superstore of quality-assured modularized learning programmes. Eur J Dent Educ 2002; 6(Suppl 3): 5-6.

16. Eaton K A, Hammick M. Distance learning materia for dentists - a user's guide to quality. Br Dent J 2003; 194: 253-256.

17. Rosell-Aguilar F. Task design for audiographic conferencing: promoting beginner oral interaction in distance language learning. Comput Assist Lang Learning 2005; 18: 417-442.

18. The Quality Assurance Agency for Higher Education. Subject overview report. Dentistry. Gloucester: QAA, 2002. http://www.qaa. ac.uk/reviews/reports/subjectlevel/q06_00.pdf (accessed 24 April 2006).

19. The Higher Education Academy. Supporting learning webpage. http://www.heacademy.ac.uk/ourwork/learning (accessed 28 April 2006)

20. Jones M L, Hobson R S, Plasschaert A J M et al. Quality assurance and benchmarking: an approach for European dental schools. Eur J Dent Educ 2007; 11: 137-143.

21. Quality for Reuse (Q4R) website. http://www.q4r. org (accessed 9 June 2008).

22. International Virtual Dental School (IVIDENT) website. http://www.ivident.info (accessed 10 June 2008) 